\title{
Influence of weather on seizure frequency - Clinical experience in the emergency room of a tertiary hospital
}

\author{
Pedro C. Brás *, Ariana Barros, Soraia Vaz, João Sequeira, Diana Melancia, Andreia Fernandes, Ary de Sousa, \\ Sara P. Dias, Inês Menezes Cordeiro, Manuel Manita
}

Serviço de Neurologia, Centro Hospitalar de Lisboa Central, EPE, Hospital Santo António dos Capuchos, Alameda Santo António dos Capuchos, 1169-050 Lisboa, Portugal

\section{A R T I C L E I N F O}

\section{Article history:}

Received 25 February 2018

Revised 5 July 2018

Accepted 12 July 2018

Available online $\mathrm{xxxx}$

\section{Keywords:}

Seizures

Epilepsy

Weather

Seasons

Sunlight

Triggers

\begin{abstract}
A B S T R A C T
Introduction: Some patients with epilepsy identify weather as a typical seizure trigger. However, it is yet to be confirmed. Thus, we aimed to evaluate possible relationships between daily meteorological conditions and the daily incidence of seizures.

Methods: This was a retrospective single center study that included adult patients who were admitted to the emergency room of a tertiary hospital in Lisbon, with a seizure, between January and December 2015. The influence of temperature, atmospheric pressure, relative humidity, wind, precipitation, sunlight duration, and the seasons on seizure frequency was evaluated.

Results: Three hundred seven seizure episodes were included (from 286 patients) in a total of 365 days, 117 (38.1\%) first unprovoked seizures and 190 (61.9\%) with previous seizure episodes. There were 82 days with higher incidence of seizures $(\geq 2)$ and 171 days without seizures. We found a statistical significant relation between lower ambient temperatures, higher atmospheric pressure, and higher maximum humidity with days with two or more seizures. We also found a statistically significant higher incidence of seizures in the winter days (p-value: 0.001 ) and in days with lower daylight duration (10.8 vs. $12.7 \mathrm{~h}$; p-value: 0.0001). With the exception of humidity, these findings remained true when analyzing the subgroup of patients with previous seizures, but there was no significant difference in the subgroup of first unprovoked seizures.

Conclusions: Our results support the possible influence of the weather on seizure frequency in the overall admissions of the emergency department of a tertiary hospital. In particular, these findings suggest that winter conditions, such as, lower ambient temperatures, higher atmospheric pressure, higher humidity, and reduced sunlight exposure, may have impact in the occurrence of higher incidence of seizures in patients with epilepsy.
\end{abstract}

c) 2018 Elsevier Inc. All rights reserved.

\section{Introduction}

The unpredictability of seizures is a concern of relevant impact in people with epilepsy. Many surveys indicate that a substantial proportion of these patients identify environmental, physical, or emotional factors that are associated with an increase in seizure frequency [1-7]. Stress is the most frequent trigger reported by patients with epilepsy, followed by sleep deprivation and tiredness. For a better seizure control, in addition to anticonvulsant therapy, avoiding seizure triggers may be important for many patients. The recognition and understanding of these triggers is therefore of significant importance.

In spite of some patients report of the weather, or weather changes, as one of their possible seizure triggers [1,7], the evidence supporting a significant influence of specific meteorological parameters in seizure

\footnotetext{
* Corresponding author.

E-mail address: pedro.costa.bras@gmail.com (P.C. Brás).
}

frequency is scarce and inconsistent [8-16]. Thus, it is still unclear what the influence of weather is on the general risk of seizures. The aim of our study was to assess if daily weather conditions and variations were associated with an increase in seizure frequency.

\section{Material and methods}

\subsection{Type of study}

This was a retrospective single-center study, based on the review of medical records of all patients observed in the emergency room assessed by a neurologist, in a tertiary hospital in Lisbon, from January to December 2015. The incidence of seizure was recorded every day.

\subsection{Population inclusion and exclusion criteria}

Patients were included in the study if they fulfilled the following criteria: 1) age older than 18 years, 2) admitted to the emergency 
room with an episode clinically compatible with a seizure, including patients with a first unprovoked seizure. Acute symptomatic seizures and seizures in noncompliant patients with epilepsy or patients with changes in antiepileptic medication in the last 3 months were excluded. In patients with more than one seizure in a 24-hour period, only one seizure was considered.

This study was approved by all relevant ethics committees.

\subsection{Data collected}

\subsubsection{Patients}

Demographic and clinical characteristics were collected for all patients, including age, gender, seizure type (generalized tonic-clonic, focal with impairment of consciousness, or focal without impairment of consciousness), and seizure time.

\subsubsection{Meteorological data}

For each day, the following data were collected from the Portuguese Institute for Sea and Atmosphere, I. P. (IPMA, IP): minimum, maximum, and mean values of daily ambient temperature $\left({ }^{\circ} \mathrm{C}\right)$; mean value of daily atmospheric pressure (hPa); minimum, maximum, and mean values of daily relative humidity (\%); mean and maximum values of daily wind ( $\mathrm{km} / \mathrm{h})$; and total daily precipitation $(\mathrm{mm})$.

Additionally, for each day, the total hours of daylight duration was collected as well.

\subsection{Statistical analysis}

A day with a higher incidence of seizures was defined as a day with more seizures than the daily average for the whole study period. We decided to use this definition to allow the inclusion of days with a higher than average frequency of seizures and exclusion of days with the mean number of seizures. By doing so, we wanted to compare days with extreme values - no seizures versus higher number of seizures - and see if the meteorological parameters were significantly different in the latter days.

Considering the whole year, we sorted out four groups: days without seizures, days with at least one seizure, days with higher seizure incidence, and a final group that includes the days before those with a higher seizure incidence.

We searched for an association between weather changes and seizures by a) comparing meteorological parameters between days with at least one seizure and days without seizures, b) comparing meteorological parameters between days with higher seizure incidence and days without seizures, c) comparing meteorological parameters between days with higher seizure incidence and the preceding days, and d) comparing the absolute 24-hour variation value of all the meteorological data between days with higher seizure incidence and days without seizures.

Finally, we compare the seizure frequency between the four seasons of the year (winter, spring, summer, and autumn).

We performed the same analysis for the two subgroups: patients with first unprovoked seizure and patients with previous seizures.

\subsection{Statistical tests}

The program SPSS 20.0 was used to conduct all statistical tests. Statistical significance of relationships was assessed with p-value $<0.05$.

Mann-Whitney tests were applied to compare medians between days with higher seizure incidence and days without seizures.

Wilcoxon signed rank tests were used to compare medians between days with higher seizure incidence and the previews days.

Kruskal-Wallis $H$ test was first performed to assess seizure frequency main effect within the four seasons of the year. Then paired Mann-Whitney tests were used to compare the seasons.

\section{Results}

In the 365-day period analyzed, from a total of 3544 urgency episodes, 532 were seizures, of which 225 were excluded, since they occurred in patients with unstable antiepileptic therapy (noncompliant patients or those with changes in antiepileptic medication in the last 3 months $)(n=155)$ or were acute symptomatic seizures $(n=70)$. A total of 307 seizures were included, the majority (87.9\%) tonic-clonic generalized seizures and $81.4 \%$ diurnal seizures (Table 1 ).

These occurred in a total of 286 patients, 165 males (57.5\%). Mean age was $54.1 \pm 20.6$ years. The mean number of seizures per patient and seizures per day were $1.07 \pm 1$ (maximum 3 ) and $0.84 \pm 1$ (maximum 5), respectively.

The group of days with no seizures comprises nearly half of the year ( $n=171,46.8 \%$ ), and the group with at least one seizure ( $\geq 1$ seizures) included the other 194 (53.2\%) days. On the other hand, 82 (22.5\%) days had two or more seizures ( $\geq 2$ seizures), so they represented the group with higher seizure incidence. The maximum number of seizures per day was 5 ( $n=3,0.82 \%)$.

In Table 2 are the results of the comparison of the meteorological data between days without seizures and days with the following: A) at least one seizure and B) higher incidence of seizures. Of relevance, there was a statistically significant lower temperature (maximum, minimum, and average) only in the days with higher seizure frequency (18.6 vs. $22.4{ }^{\circ} \mathrm{C}$, p-value: $0.004 ; 11.3$ vs. $14.2^{\circ} \mathrm{C}$, p-value: 0.001 ; and 15 vs. $17.5^{\circ} \mathrm{C}$, p-value: 0.002 ) (Fig. $\left.1 . a\right)$. In addition, we found a statistically significant higher atmospheric pressure ( 1022.6 vs. $1018.6 \mathrm{hPa}$; pvalue: 0.003 ) (Fig. 1.b) and higher maximum humidity (97 vs. 94\%; pvalue: 0.043 ) (Fig. 1.c) only in days with two or more seizures. However, when comparing days without seizures with days with at least one seizure there were not a statistically significant difference between them.

The number of hours of daylight duration was significantly lower on days with at least one seizure (11.8 vs. $12.7 \mathrm{~h}$; p-value: 0.019 ) and in days with two or more seizures (10.8 vs. $12.7 \mathrm{~h}$; p-value: 0.0001 ).

No difference was found in any meteorological data between the days with higher incidence of seizures and the days before these.

As shown in Fig. 2, the seizure distribution by season revealed a peak in winter (34.5\%) and a nadir in spring (19.2\%). Thereafter, seizure counts progressively increased: $21.8 \%$ in summer and $24.4 \%$ in autumn.

The Kruskal-Wallis $H$ test revealed a statistically significant difference in seizure frequency between the different seasons, with a main effect of $\chi 2(2)=14.655$, p-value: 0.002 (with a mean rank seizure frequency of 214.76 for winter, 161.15 for spring, 174.27 for summer, and 183.15 for autumn) (Fig. 2). Posthoc comparison of winter seizure frequency with those of the other seasons revealed significant difference for spring $(\mathrm{p}=0.0003)$, summer $(\mathrm{p}=0.004)$, and autumn $(\mathrm{p}=$ 0.038 ). The difference between the percentage averages in winter and spring was $28.4 \%$.

In the subgroup of first unprovoked seizures, with 117 episodes, the analysis revealed no statistically significant difference between days without seizures and days with higher seizure incidence (Table 3). However, in the other subgroup, with 190 seizures in patients with previous seizures, the same statistical significant difference described above for the all group was identified, with the exception for humidity (p-value: 0.098) (Table 4).

Table 1

Seizures characteristics, $\mathrm{n}=307$.

\begin{tabular}{ll}
\hline & $\mathrm{n}(\%)$ \\
\hline First seizure & $117(38.1)$ \\
$\begin{array}{l}\text { Nocturne seizure } \\
\text { Seizure type }\end{array} \quad 57(18.6)$ \\
$\quad$ Generalized tonic-clonic & $270(87.9)$ \\
$\quad$ Focal with impairment of consciousness & $18(5.9)$ \\
$\quad$ Focal without impairment of consciousness & $19(6.2)$ \\
\hline
\end{tabular}


Table 2

Comparison of the meteorological data between days without seizures and: A) days with at least one seizure; B) days with higher incidence of seizures.

\begin{tabular}{|c|c|c|c|c|c|}
\hline & \multirow[b]{2}{*}{$\begin{array}{l}\text { Days without seizures } \\
(\mathrm{n}=171)\end{array}$} & \multicolumn{2}{|l|}{ A } & \multicolumn{2}{|l|}{$\mathrm{B}$} \\
\hline & & $\begin{array}{l}\text { Days with } \geq 1 \text { seizure } \\
(\mathrm{n}=194)\end{array}$ & p-Value* & $\begin{array}{l}\text { Days with } \geq 2 \text { seizures } \\
(\mathrm{n}=82)\end{array}$ & $\overline{p-V a l u e}{ }^{*}$ \\
\hline \multicolumn{6}{|c|}{ Ambient temperature, ${ }^{\circ} \mathrm{C}$} \\
\hline Minimum & $14.2(10.8-16.9)$ & $13.0(10.0-16.4)$ & 0.067 & $11.3(8.6-15.8)$ & 0.001 \\
\hline Maximum & $22.4(18.5-27.3)$ & $20.6(16.5-26.4)$ & 0.055 & $18.6(15.7-24.5)$ & 0.002 \\
\hline Average & $17.5(14.3-20.9)$ & $16.4(13.0-20.4)$ & 0.076 & $15(11.5-18.9)$ & 0.002 \\
\hline \multicolumn{6}{|c|}{ Relative humidity, \% } \\
\hline \multirow[t]{2}{*}{ Minimum } & $49(39-60)$ & $49(38-63.5)$ & 0.510 & $52.5(41-63.5)$ & 0.198 \\
\hline & $49.8 \pm 17.8$ & $51.5 \pm 19.8$ & & $52.9 \pm 18.9$ & \\
\hline \multirow[t]{2}{*}{ Maximum } & $100(92-100)$ & $100(91.8-100)$ & 0.709 & $100(97.5-100)$ & 0.043 \\
\hline & $94.2 \pm 10.5$ & $94.2 \pm 10.8$ & & $96.7 \pm 6.8$ & \\
\hline \multirow{2}{*}{ Average } & $76(66-85)$ & $77(65-88.3)$ & 0.527 & $80(70-90)$ & 0.152 \\
\hline & $75 \pm 15.4$ & $76 \pm 16.1$ & & $78.1 \pm 14.4$ & \\
\hline \multicolumn{6}{|c|}{ Atmospheric pressure, $h \mathrm{~Pa}$} \\
\hline \multirow[t]{2}{*}{ Average } & 1018.6 & 1019.1 & 0.286 & 1022.6 & 0.003 \\
\hline & $(1016.2-1023.1)$ & $(1016.1-1026.2)$ & & $(1017-1029)$ & \\
\hline \multicolumn{6}{|l|}{ Wind, $\mathrm{km} / \mathrm{h}$} \\
\hline Maximum & $10.6(8.1-12.7)$ & $10.8(8.6-13.5)$ & 0.481 & $10.1(8-13.4)$ & 0.724 \\
\hline Average & $3.3(2.6-4.1)$ & $3.4(2.7-4.3)$ & 0.333 & $3.5(3.5-4.3)$ & 0.754 \\
\hline \multicolumn{6}{|c|}{ Precipitation, mm } \\
\hline Total & $1.4 \pm 4.9$ & $1.4 \pm 4.5$ & 0.378 & $0.9 \pm 2.4$ & 0.886 \\
\hline
\end{tabular}

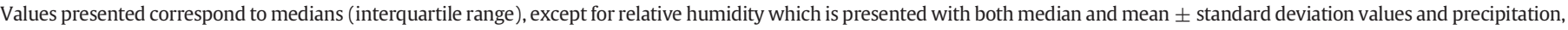
which is presented with the mean \pm standard deviation values.

* p-Value of Mann-Whitney tests performed.

\section{Discussion}

The present study revealed a significant relationship between the occurrence of days with a higher incidence of seizures in the overall admissions of an emergency department and some weather factors, namely temperature, atmospheric pressure, and humidity. Of note, these findings did not hold true for days with at least one seizure, reinforcing the idea that weather conditions can influence a higher seizure frequency.

When performing the same analysis for the two subgroups of seizures separately, the same results remained true only for days with seizures in patients with previous episodes. This difference is indicative that patients with epilepsy have a higher susceptibility to weather conditions and supports its possible influence in reducing their epileptic threshold. Patients with a first unprovoked seizure represent a more heterogeneous group and only some of them really have epilepsy.

\subsection{Ambient temperature}

Concerning the effects of temperature, our findings suggest a relationship between low temperatures and seizures. Indeed, the influence of low temperatures and winter days with the increase of seizure risk has been already suggested in previous studies $[10,13]$. Motta et al. analyzed electroencephalograph (EEG) recordings in different seasons and showed that the smallest proportion of normal EEG recordings was noted in winter, and epileptiform discharges were noted more frequently in winter [13]. Similarly, Danesi et al. recorded EEG in various seasons among patients susceptible to photic stimulation and found that epileptiform discharges were most prevalent in winter. This author proposed that these unclear results might be related with the lower air temperature and insolation in winter [10]. Recently, in line with our findings, Rakers et al. found that high ambient temperatures of $>20^{\circ} \mathrm{C}$ decreased seizure risk by $46 \%$ in the overall study population (OR: 0.54, 95\% CI: 0.32-0.90) [16]. Likewise, Ruegg et al. also described the same protective effect of high temperature in the incidence of status epilepticus [14].
The reproducibility of all these findings toward the same direction may suggest a significant impact of low temperature and/or winter days in the pathophysiology of seizures initiation.

\subsection{Atmospheric pressure}

We found a possible effect from higher atmospheric pressure on seizure frequency. However, these results are in disagreement with others previously reported $[11,16]$. Doherty et al. found no evidence of a relation between atmospheric pressure changes and seizure occurrence in an epilepsy monitoring unit [11]. On the other hand, Rakers et al. found that for every 10.7-hPa lower atmospheric pressure, seizure risk increased in the entire study population by $14 \%$ (OR: $1.14,95 \% \mathrm{CI}$ : 1.01-1.28) [16]. In spite of the exact mechanisms for this being still unclear, a study in rats has shown that lowering the atmospheric pressure in an air pressure chamber increased neuronal activity [17].

\subsection{Relative air humidity}

Finally, we also found a significant relation between higher humidity levels and seizures. This findings were similar to those previously described by Rakers et al., who reported that a high relative air humidity of $>80 \%$ increased seizure risk in the entire study population by up to 48\% (OR: 1.48, 95\% CI: 1.11-1.96) 3 days after exposure [16]. In contrast to our results, Ruegg et al. described that a high relative air humidity is a protective factor for epileptic seizures; however, this study was conducted on patients with status epilepticus admitted to the intensive care unit [14].

\subsection{Winter}

Grouping all the above-mentioned results, we can say that lower temperatures, higher atmospheric pressure, and higher humidity have in common most frequently occurring in winter days. In fact, we found a statistically significant increased seizure frequency in winter compared with all the other seasons (Fig. 2), revealing a seasonal distribution of seizures. Besides, the average difference between winter and 

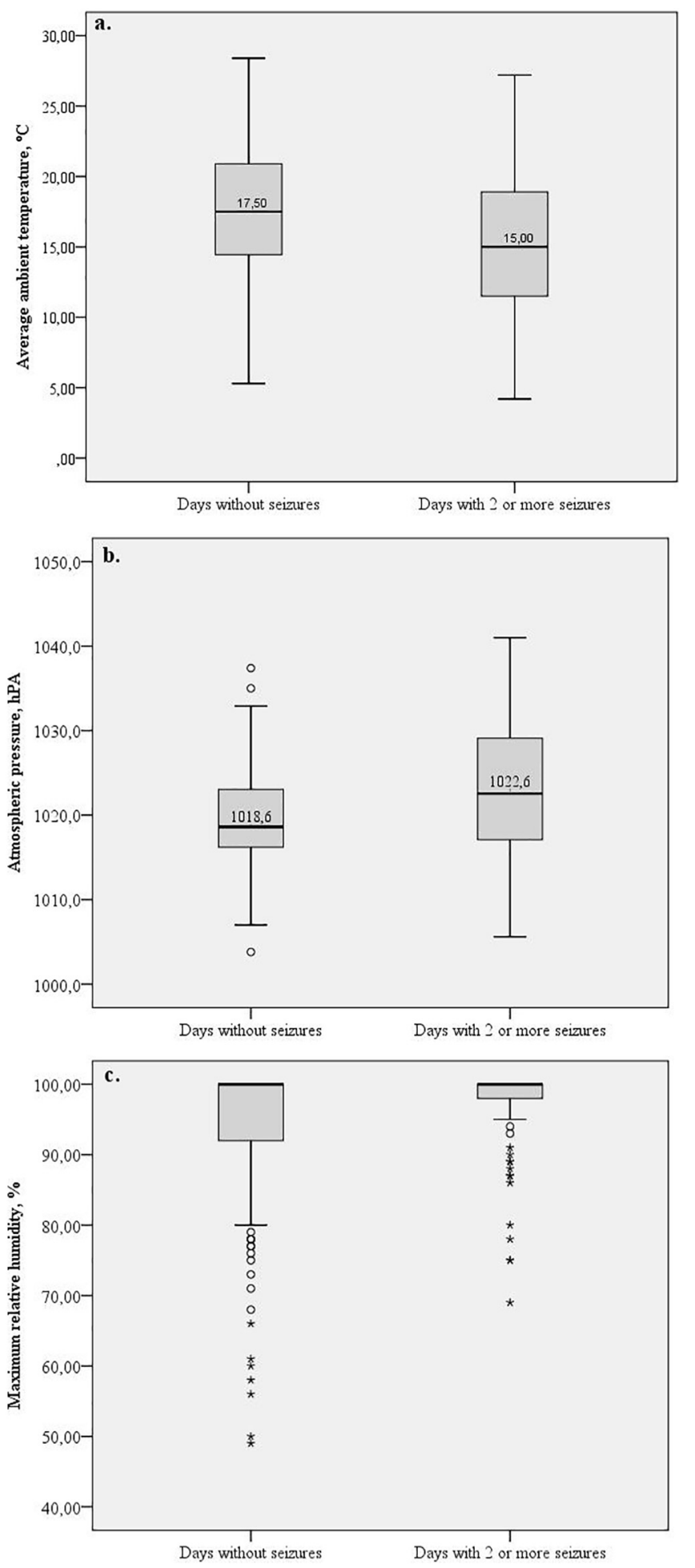

Fig. 1. Boxplot of the three meteorological parameters with statistical significance in seizures incidence: a. ambient temperature, b. atmospheric pressure, and c. maximum relative humidity. Comparison between days without seizures and the days with higher incidence of seizures.

spring, accounting for $28 \%$, is substantial. These results are in line with those of Clemens et al. who found a similar difference of $31.1 \%$ between January and August [18].

We can speculate that other nonmeteorological factors related to winter days might exist, which could also increase the risk of seizure occurrence in our study population. One possible factor could be the lower duration of sun exposure during winter days, as already proposed by

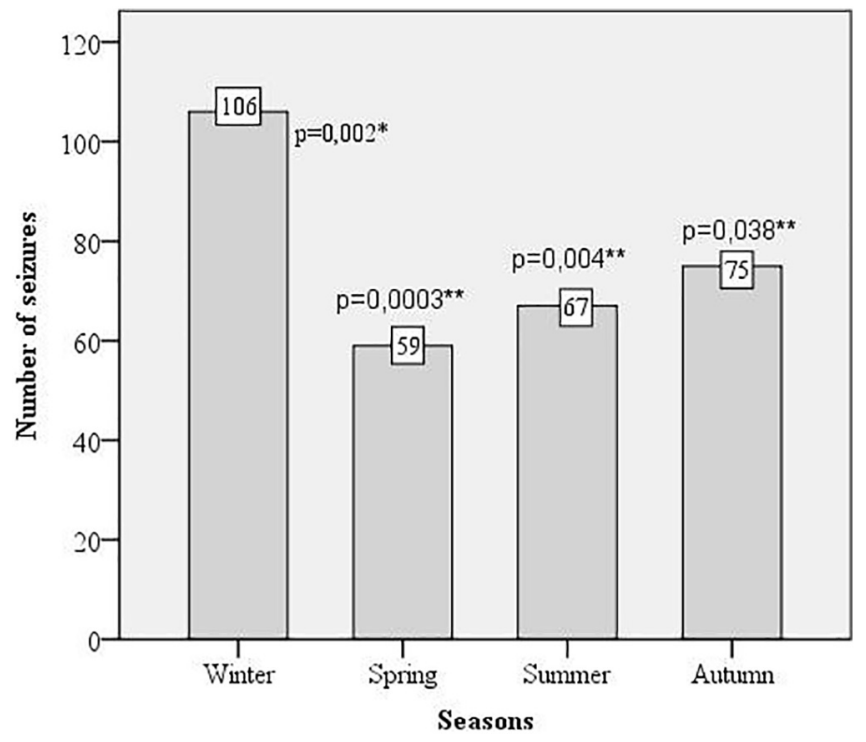

Fig. 2. Distribution of seizures for each season in the year. ${ }^{*}$-Value of Kruskal-Wallis $H$ Test for comparison between the four seasons. ${ }^{* *}$ p-Value of Mann-Whitney posthoc comparison of winter with those of the other seasons.

Danesi et al. Our analysis revealed a lower daylight duration in days with higher incidence of seizures (10.8 vs. $12.7 \mathrm{~h}$; p-value: 0.0001 ). These findings are in agreement with what was suggested by Danesi et al. - brain excitability is possibly related with the number of hours exposed to sunlight [10]. Baxendale also found that epileptic seizures were less likely to occur in bright sunny days, than in dull days [19]. One possible explanation could be the seasonal fluctuations of melatonin secretion, with higher levels in winter [20,21]. However, in spite of some of the reports found that melatonin can raise the risk of seizures, the effect of this hormone on seizure frequency is still controversial [22]. Another potential reason could be the lower vitamin D levels, which fall significantly during winter, as already suggested in other

Table 3

Comparison of the meteorological data including only the subgroup of first unprovoked seizures, between days without seizures and days with higher incidence of seizures.

\begin{tabular}{|c|c|c|c|}
\hline & $\begin{array}{l}\text { Days without } \\
\text { seizures } \\
(\mathrm{n}=266)\end{array}$ & $\begin{array}{l}\text { Days with first unprovoked } \\
\text { seizures } \\
(\mathrm{n}=99)\end{array}$ & p-Value* \\
\hline \multicolumn{4}{|c|}{ Ambient temperature, ${ }^{\circ} \mathrm{C}$} \\
\hline Minimum & $13.7(10.4-16.9)$ & $13(10.1-16.2)$ & 0.268 \\
\hline Maximum & $21.9(17.5-27.2)$ & $20.6(17-26.3)$ & 0.349 \\
\hline Average & $17.2(13.5-20.9)$ & $16.4(13.4-19.6)$ & 0.270 \\
\hline \multicolumn{4}{|c|}{ Relative humidity, \% } \\
\hline \multirow[t]{2}{*}{ Minimum } & $49(37.8-61)$ & $49(39-62)$ & 0.954 \\
\hline & $50.8 \pm 19.6$ & $50.3 \pm 17$ & \\
\hline \multirow[t]{2}{*}{ Maximum } & $100(92-100)$ & $100(94-100)$ & 0.630 \\
\hline & $94 \pm 10.9$ & $94.9 \pm 9.6$ & \\
\hline \multirow[t]{2}{*}{ Average } & $76(65-88)$ & $77(67-88)$ & 0.836 \\
\hline & $75.4 \pm 16.1$ & $75.9 \pm 14.9$ & \\
\hline \multicolumn{4}{|c|}{ Atmospheric pressure, $h \mathrm{~Pa}$} \\
\hline Average & $\begin{array}{l}1018.7 \\
(1016.2-1024.1)\end{array}$ & $\begin{array}{l}1019.2 \\
(1016.1-1026.1)\end{array}$ & 0.400 \\
\hline \multicolumn{4}{|l|}{ Wind, $\mathrm{km} / \mathrm{h}$} \\
\hline Maximum & $10.7(8.2-13.5)$ & $10.3(8.8-13)$ & 0.693 \\
\hline Average & $3.4(2.7-4.2)$ & $3.2(2.6-4.2)$ & 0.456 \\
\hline \multicolumn{4}{|c|}{ Precipitation, mm } \\
\hline Total & $1.4 \pm 4.8$ & $1.2 \pm 4.4$ & 0.916 \\
\hline
\end{tabular}

Values presented correspond to medians (interquartile range), expect for relative humidity, which is presented with both median and mean \pm standard deviation values and precipitation, which is presented with the mean \pm standard deviation values.

* p-Value of Mann-Whitney tests performed. 
Table 4

Comparison of the meteorological data including only the subgroup of seizures with previous episodes, between days without seizures and days with higher incidence of seizures.

\begin{tabular}{|c|c|c|c|}
\hline & $\begin{array}{l}\text { Days without } \\
\text { seizures } \\
(\mathrm{n}=226)\end{array}$ & $\begin{array}{l}\text { Days with seizures with previous } \\
\text { episodes } \\
(\mathrm{n}=139)\end{array}$ & p-Value* \\
\hline \multicolumn{4}{|c|}{ Ambient temperature, ${ }^{\circ} \mathrm{C}$} \\
\hline Minimum & $14.1(10.9-16.9)$ & $12(9.2-16.5)$ & 0.011 \\
\hline Maximum & $22.3(18.6-27.4)$ & $19.6(15.9-26.1)$ & 0.006 \\
\hline Average & $17.6(14.3-20.9)$ & $15.2(12.1-20.2)$ & 0.011 \\
\hline \multicolumn{4}{|c|}{ Relative humidity, \% } \\
\hline \multirow[t]{2}{*}{ Minimum } & $48(36-60)$ & $50(40-66)$ & 0.164 \\
\hline & $49.5 \pm 17.7$ & $52.7 \pm 20.5$ & \\
\hline \multirow[t]{2}{*}{ Maximum } & $100(92-100)$ & $100(93-100)$ & 0.098 \\
\hline & $93.9 \pm 10.6$ & $94.7 \pm 10.6$ & \\
\hline \multirow[t]{2}{*}{ Average } & $76(65-86)$ & $79(67-89)$ & 0.163 \\
\hline & $74.7 \pm 15.5$ & $76.9 \pm 16$ & \\
\hline \multicolumn{4}{|c|}{ Atmospheric pressure, $h \mathrm{~Pa}$} \\
\hline Average & $\begin{array}{l}1018.4 \\
(1015.9-1023.2)\end{array}$ & $\begin{array}{l}1019.6 \\
(1016.6-1027.3)\end{array}$ & 0.021 \\
\hline \multicolumn{4}{|l|}{ Wind, $\mathrm{km} / \mathrm{h}$} \\
\hline Maximum & $10.7(8.6-13)$ & $10.4(8.2-13.7)$ & 0.770 \\
\hline Average & $3.3(2.6-4.2)$ & $3.5(2.7-4.4)$ & 0.124 \\
\hline \multicolumn{4}{|c|}{ Precipitation, $\mathrm{mm}$} \\
\hline Total & $1.4 \pm 5$ & $1.3 \pm 4.1$ & 0.520 \\
\hline
\end{tabular}

Values presented correspond to medians (interquartile range), expect for relative humidity, which is presented with both median and mean \pm standard deviation values and precipitation, which is presented with the mean \pm standard deviation values.

* p-Value of Mann-Whitney tests performed.

studies [18]. Indeed, a few studies have demonstrated a possible anticonvulsant effect of vitamin $\mathrm{D}[23,24]$, so the seasonal variation in seizures could be viewed as an indirect effect of low levels of vitamin $\mathrm{D}$, which could be involved in the pathophysiology of seizure initiation.

Whether these meteorological and nonmeteorological factors related to winter work independently or synergically is unclear. Based on our findings, we believe that the multitude of variables associated with winter had contributed together to the increase of seizure incidence in our study population.

\subsection{Study strengths and limitations}

One of the strengths that our study has is the inclusion of a broad population comprising outpatients with or without previously diagnosed epilepsy. It also involved the analysis of an entire year period, which allowed the inclusion of all the seasons of the year and weather variability.

One of the limitations of our work is its retrospective nature, basing the diagnosis of a seizure only in clinical data described in each day. Another limitation is that the seizure frequency was based only in the admissions to the emergency department. Therefore, the present study cannot make conclusions about the global seizure frequency. However, we can make some conclusions about the seizure frequency in the global emergency admissions of the hospital in one entire year.

\section{Conclusions}

In this study, the incidence of seizure admissions in an emergency room was higher in relation with the following: a) lower temperatures, higher atmospheric pressure, and higher humidity; b) days with lower sunlight duration; and c) winter days.

We suggest that winter associated factors (both meteorological and nonmeteorological) contribute to a higher seizure incidence. For instance, reduced light exposure could influence seizure seasonality by inducing hormonal fluctuations, like melatonin or vitamin D.

Our findings are important as they support the subjective idea of some patients that seizure risk increases with certain weather conditions. However, besides the apparent consensual and unexplained effect of low ambient temperature on seizures, all the other meteorological parameters appears to be more controversial. These contradictory results remain to be clarified. Few reports still exist in the literature to elucidate the impact of weather on epilepsy. Furthermore, very different study populations and clinical scenarios in all those existing studies make it even more difficult for its interpretation and comparison.

Investigating potential relationships between environmental factors and the occurrence of seizures is important, as it may contribute to a better understanding of mechanisms underlying the generation of seizures and could potentially suggest behavioral management strategies for reducing seizure occurrence. Moreover, the seasonal distribution of seizures should be considered in assessing the efficacy of antiepileptic drugs.

\section{Funding}

This research did not receive any specific grant from funding agencies in the public, commercial, or not-for-profit sectors.

\section{Conflicts of interest}

None.

\section{References}

[1] Balamurugan E, Aggarwal M, Lamba A, Dang N, Tripathi M. Perceived trigger factors of seizures in persons with epilepsy. Seizure 2013;22(9):743-7.

[2] Dionisio J, Tatum 4th WO. Triggers and techniques in termination of partial seizures. Epilepsy Behav 2010;17(2):210-4.

[3] Ferlisi M, Shorvon S. Seizure precipitants (triggering factors) in patients with epilepsy. Epilepsy Behav 2014;33:101-5.

[4] Nakken KO, Solaas MH, Kjeldsen MJ, Friis ML, Pellock JM, Corey LA. Which seizureprecipitating factors do patients with epilepsy most frequently report? Epilepsy Behav 2005;6(1):85-9.

[5] Sperling MR, Schilling CA, Glosser D, Tracy JI, Asadi-Pooya AA. Self-perception of seizure precipitants and their relation to anxiety level, depression, and health locus of control in epilepsy. Seizure 2008;17(4):302-7.

[6] Illingworth JL, Watson P, Ring H. Why do seizures occur when they do? Situations perceived to be associated with increased or decreased seizure likelihood in people with epilepsy and intellectual disability. Epilepsy Behav 2014;39:78-84.

[7] Spatt J, Langbauer G, Mamoli B. Subjective perception of seizure precipitants: results of a questionnaire study. Seizure1059-1311 1998;7:391-5 [Print].

[8] Altimiras-Roset J, Brunet-Gomez A, Aragones J, Roura-Poch P. Influence of meteorological and chronological factors in epilepsy. Rev Neurol 2014;59(8):345-8.

[9] Asensi F, Devesa F, Fillol M. Meteorotropism of seizures in children from birth to seven years (author's transl). An Esp Pediatr 1977;10(6-7):506-13.

[10] Danesi MA. Seasonal variations in the incidence of photoparoxysmal response to stimulation among photosensitive epileptic patients: evidence from repeated EEG recordings. J Neurol Neurosurg Psychiatry 1988;51(6):875-7.

[11] Doherty MJ, Kim W, Youn CE, Oakley JC, Drane DL, Miller JW. Do atmospheric pressure changes influence seizure occurrence in the epilepsy monitoring unit? Epilepsy Behav 2009;16(1):80-1.

[12] Doherty MJ, Youn C, Gwinn RP, Haltiner AM. Atmospheric pressure and seizure frequency in the epilepsy unit: preliminary observations. Epilepsia 2007;48(9):1764-7.

[13] Motta E, Golba A, Bal A, Kazibutowska Z, Strzała-Orzeł M. Seizure frequency and bioelectric brain activity in epileptic patients in stable and unstable atmospheric pressure and temperature in different seasons of the year - a preliminary report. Neurol Neurochir Pol 2011;45(6):561-6.

[14] Ruegg S, Hunziker P, Marsch S, Schindler C. Association of environmental factors with the onset of status epilepticus. Epilepsy Behav 2008;12(1):66-73.

[15] Ruhenstroth-Bauer G, Baumer H, Kugler J, Spatz R, Sönning W, Filipiak B. Epilepsy and weather: a significant correlation between the onset of epileptic seizures and specific atmospherics - a pilot study. Int J Biometeorol 1984;28(4):333-40.

[16] Rakers F, Walther M, Schiffner R, Rupprecht S, Rasche M, Kockler M, et al. Weather as a risk factor for epileptic seizures: a case-crossover study. Epilepsia1528-1167 2017; 58(7):1287-95 [Electronic].

[17] Messlinger K, Funakubo M, Sato J, Mizumura K. Increases in neuronal activity in rat spinal trigeminal nucleus following changes in barometric pressure - relevance for weather-associated headaches? Headache J Head Face Pain1526-4610 2010;50(9) [Electronic].

[18] Clemens Z, Holló A, Kelemen A, Rásonyi G, Fabó D, Halász P, et al. Seasonality in epileptic seizures. J Neurol Transl Neurosci 2013;1(1016).

[19] Baxendale S. Seeing the light? Seizures and sunlight. Epilepsy Res1872-6844 2009; 84:72-6 [Electronic]

[20] Morera AL, Abreu P. Seasonality of psychopathology and circannual melatonin rhythm. J Pineal Res0742-3098 2006;41(3):279-83. 
[21] Kivela A, Kauppila A, Ylostalo P, Vakkuri O, Leppäluoto J. Seasonal, menstrual and circadian secretions of melatonin, gonadotropins and prolactin in women. Acta Physiol0001-6772 1988;13(3):321-7 [Print].

[22] Jain S, Besag FM. Does melatonin affect epileptic seizures? Drug Saf1179-1942 2013; 36(4):207-15 [Electronic].
[23] Holló A, Clemens Z, Kamondi A, Lakatos P, Szücs A. Correction of vitamin D deficiency improves seizure control in epilepsy: a pilot study. Epilepsy Behav 2012;24 (1):131-3.

[24] Christiansen C, Rodbro P, Sjö O. "Anticonvulsant action" of vitamin D in epileptic patients? A controlled pilot study. Br Med J0007-1447 1974;2:258-9 [Print]. 